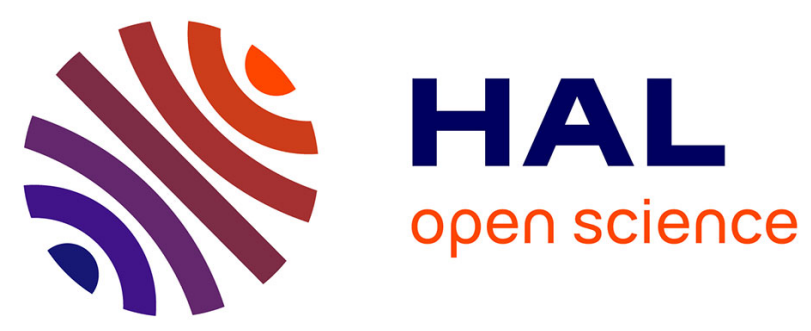

\title{
Association of education and receiving social transfers with allostatic load in the Swiss population-based CoLaus study
}

Edouard Nicod, Silvia Stringhini, Pedro Marques-Vidal, Fred Paccaud, Gérard Waeber, Karine Lamiraud, Peter Vollenweider, Muriel Bochud

\section{To cite this version:}

Edouard Nicod, Silvia Stringhini, Pedro Marques-Vidal, Fred Paccaud, Gérard Waeber, et al.. Association of education and receiving social transfers with allostatic load in the Swiss population-based CoLaus study. 2014. hal-01062282

\section{HAL Id: hal-01062282 \\ https://essec.hal.science/hal-01062282}

Preprint submitted on 9 Sep 2014

HAL is a multi-disciplinary open access archive for the deposit and dissemination of scientific research documents, whether they are published or not. The documents may come from teaching and research institutions in France or abroad, or from public or private research centers.
L'archive ouverte pluridisciplinaire HAL, est destinée au dépôt et à la diffusion de documents scientifiques de niveau recherche, publiés ou non, émanant des établissements d'enseignement et de recherche français ou étrangers, des laboratoires publics ou privés. 


\section{Association of education and receiving social transfers with allostatic load in the Swiss population-based CoLaus study}

\section{Research Center \\ ESSEC Working Paper 1412}

\section{4}

Edouard Nicod Silvia Stringhini Pedro Marques-Vidal Fred Paccaud Gérard Waeber Karine Lamiraud Peter Vollenweider Murielle Bochud 


\section{Association of education and receiving social transfers with allostatic load in the Swiss}

\section{population-based CoLaus study}

Edouard Nicod $^{1 *}$, Silvia Stringhini ${ }^{1 *}$, Pedro Marques-Vidal $^{1}$, Fred Paccaud $^{1}$, Gérard Waeber $^{2}$, Karine Lamiraud $^{3}$, Peter Vollenweider ${ }^{2}$, Murielle Bochud $^{1 * *}$

1 Institute of Social and Preventive Medicine (IUMSP), Lausanne University Hospital,

Lausanne, Switzerland, 2 Department of Medicine, Internal Medicine, Lausanne University

Hospital, Lausanne, Switzerland, 3 ESSEC Business School, Paris, France

* These authors contributed equally to this work

** Corresponding author: Prof Murielle Bochud, MD, PhD, Institute of Social and Preventive

Medicine, Route de la Corniche 10, CH- 1010 Lausanne, Switzerland, E-mail :

Murielle.Bochud@,chuv.ch

Running Title: Socioeconomic status and allostatic load 


\begin{abstract}
Background. Allostatic load reflects cumulative exposure to stressors throughout lifetime and has been associated with several adverse health outcomes. It is hypothesized that people with low socioeconomic status (SES) are exposed to higher chronic stress and have therefore greater levels of allostatic load.
\end{abstract}

Objective. To assess the association of receiving social transfers and low education with allostatic load.

Methods. We included 3'589 participants (1'812 women) aged over 35 years and under retirement age from the population-based CoLaus study (Lausanne, Switzerland, 2003-2006). We computed an allostatic load index aggregating cardiovascular, metabolic, dyslipidemic and inflammatory markers. A novel index additionally including markers of oxidative stress was also examined.

Results. Men with low vs high SES were more likely to have higher levels of allostatic load (Odds ratio $(\mathrm{OR})=1.93 / 2.34$ for social transfers/education,95\%CI from 1.45 to 4.17 ). The same patterns were observed among women. Associations persisted after controlling for health behaviors and marital status.

Conclusions. Low education and receiving social transfers independently and cumulatively predict high allostatic load and dysregulation of several homeostatic systems in a Swiss population-based study. Participants with low SES are at higher risk of oxidative stress, which may justify its inclusion as a separate component of allostatic load.

Keywords. Allostatic load; Socioeconomic status; Chronic stress; Oxidative stress; population-based; education 


\section{INTRODUCTION}

An association between socioeconomic status (SES) and health, with lower SES being associated with poorer health in a dose-response manner, has been extensively documented and is consistently found across health outcomes, places and time (Adler et al., 1994; Marmot and Wilkinson, 2006). SES differences in health can be found even in prosperous countries such as Switzerland, which ranked $11^{\text {th }}$ in the 2011 Human Development Index (UNDP, 2011) and has one of the highest gross domestic product per capita in the world (World Bank, 2012). The socioeconomic gradient in health seems to be even steeper in Switzerland than in other European countries, at least in men (Bopp and Minder, 2003).

Among the factors that have been proposed to explain social inequalities in health are a higher exposure of low SES individuals to environmental factors such as air pollution (Evans and Kantrowitz, 2002; Forastiere et al., 2007), psychosocial factors such as stress (Kristenson et al., 2004; McCartney et al., 2012; Pearlin et al., 2005) or health-risk behaviors such as smoking (Stringhini et al., 2010). Recently, research has started addressing the issue of how SES is biologically embedded to generate differences in health (Hertzman, 1999; Hertzman and Boyce, 2010; Seeman et al., 2010). In this context, the pathway of chronic stress has received a lot of attention.

The concept of allostatic load (AL) has been introduced in the early 1990s by McEwen and Stellar to represent the physiological consequences of exposure to chronic stress (McEwen, 1998, 2004; McEwen and Stellar, 1993). AL is generally operationalized through an index, which is an indicator of the cumulative physiological toll on multiple biological systems over the years (Seeman et al., 2010). Several studies have shown AL to capture the physiological dysregulation that occurs in response to chronic stress (Gallo et al., 2011; Juster et al., 2011). AL has also been associated with cardiovascular morbidity and mortality (Crimmins et al., 2003; Seeman et al., 2004; Seeman et al., 2001), as well as with poorer cognitive and physical functioning (Juster et al., 2010; Seeman et al., 1997).

Studies that have investigated the relationship between SES and AL have generally observed strong SES gradients in cumulative physiological dysregulation (Gruenewald et al., 2012; Seeman et al., 2010). Moreover, in one study SES associated differences in AL were shown to explain up to one third of SES differences in mortality (Seeman et al., 2004). 
Studies have examined a variety of indicators of SES in relation to AL (Dowd et al., 2009), including education(Hu et al., 2007; Seeman et al., 2004), income (Hu et al., 2007) and socioeconomic disadvantage (Gruenewald et al., 2012). However, which component of low SES (i.e. financial adversity, lack of coping resources, or deleterious lifestyle) represent a challenge for physiological dysregulation is still not clear. Moreover, most studies in this area have been conducted in North American populations (United States) and it remains to be known if SES differences in AL exist even in prosperous countries where health insurance is mandatory and access to health-care is relatively universal.

Although there is still an ongoing debate on which is the best way to capture the multiple and interrelated components of AL (Seeman et al., 2010), studies have generally operationalized AL by creating an index aggregating cardiovascular, metabolic, dyslipidemic, neuroendocrine and inflammatory markers.

To our knowledge, no component specifically targeting oxidative stress has been used so far when generating AL, although mammalian organisms under chronic stress display increased oxidative stress at the cellular level(Devaki et al., 2013). Oxidative stress results from an imbalance between pro- and anti-oxidant molecules, which leads to cell damage. Reactive derivatives of oxygen or nitrogen are the hallmark of oxidative stress, but their instability precludes their use as biomarkers. Serum gamma-glutamyltransferase (GGT) is considered as a suitable marker for oxidative stress in epidemiological settings (Lee et al., 2004). Both homocystein (Liu et al., 2013) and uric acid (So and Thorens, 2010; Strazzullo and Puig, 2007) are considered as markers of oxidative stress and their circulating levels can be easily assessed in large scale population-based studies.

As most studies assessing the association between SES and AL have been conducted in North American populations, the first objective of the present study is to assess whether SES is associated with allostatic load also in a Swiss population-based study (Colaus). In this context, we use two indicators of SES, education, which has been consistently found to be associated with AL in previous studies, and receiving social transfers, which we consider here as a proxy indicator of financial difficulties. The second objective of this study is to compare two indexes of allostatic load, a "classic" index aggregating cardiovascular, metabolic, dyslipidemic and inflammatory markers, and a novel index additionally including markers of oxidative stress, in relation to SES. 


\section{DATA AND METHODS}

\section{Study population}

The CoLaus Study was implemented in Lausanne, a French-speaking Swiss town counting approximately 120,000 inhabitants, after approval of the Institutional Ethics Committee of the University of Lausanne. Participants' recruitment took place between June 2003 and May 2006 at the University Hospital of Lausanne (CHUV). A random sample of 19,830 subjects ( $35 \%$ of registered Swiss citizens) was drawn, out of which 8,121 subjects ( $41 \%$ of the random sample) agreed to participate. Individuals who had moved out of Lausanne, who had died in 2003 or who didn't meet the age criteria were considered as non-eligible. Out of the 8,121 subjects, only 6,738 completed the interview, from which 549 subjects were withdrawn because they were non-Caucasian and one person self-withdrew, reducing the final sample size to 6,188 . Further details on sampling, recruitment and inclusion criteria are provided in Firmann et al (Firmann et al., 2008).

Data were collected by trained research nurses, supervised by a medical doctor and a senior research nurse. Venous blood samples were drawn after an overnight fast, and assays were performed by on fresh plasma samples within 2 hour of blood collection in a Modular $\mathrm{P}$ apparatus (Roche Diagnostics, Switzerland). Information on demographic data, socioeconomic and marital status, lifestyle factors, personal and family history of disease, cardiovascular risk factors and treatment was collected through questionnaire.

\section{Measures}

\section{Socioeconomic status (SES)}

Two indicators of SES were used: receiving social transfers (ST) and educational level. Social transfer status was assessed with the question: "Do you receive social help (for instance for the health insurance, retirement benefits or the invalidity insurance)?" Answer: "Yes/No". In Switzerland, social transfers are provided as financial support by the government to people with disabilities, whose income is insufficient to support themselves or their family, or who are retired (Statistique suisse, 2012). Because all individuals residing in Switzerland receive financial compensation when they retire, the response to this variable is not informative beyond the retirement age. Therefore, men older than 65 years and women older than 63 or 64 years were excluded from the analyses $(\mathrm{N}=1110)$. More precisely, because women age at retirement changed over the recruitment period, if the examination took place before January 
$1^{\text {st }} 2005$, we dropped women older than 63 , otherwise we dropped only those older than 64 ( Jacques Méry, OFAS. Statistique de l'AVS 2009, p. 26).

Educational level was categorized as (1) primary education $(20.1 \%)$, (2) vocational secondary education $(24.3 \%)$, (3) secondary education (36.6\%) and (4) university (19\%) as described in Firmann et al (Firmann et al., 2008).

In order to examine the cumulative impact of low education and receiving social transfers on physiological dysregulation, we built a SES score combining both indicators. Only for constructing a SES score, education was further dichotomized as high (secondary education or university) or low (primary education or vocational secondary education). The SES score was then calculated as follows: (1) high education and no ST, (2) high education and ST, (3) low education and no ST and (4) low education and ST.

\section{Other covariates}

Marital status, that can be considered and indicator of social support (Stringhini et al., 2012), was categorized as single, married or living in couple, divorced, or widowed. Smoking was classified as current or non-current smoking. Alcohol consumption was categorized into regular alcohol intake (at least 1/unit of alcohol per day, corresponding to 10 grams of alcohol) versus non-regular alcohol intake. Physical activity was dichotomized into never versus at least once per week with respect to leisure physical activity sessions (jogging, swimming, cycling, etc.) of at least 20 minutes.

\section{Clinical and biological data}

Body weight $(\mathrm{kg})$, height $(\mathrm{cm})$, and waist and hip circumferences $(\mathrm{cm})$ were measured according to standard procedures (Firmann et al., 2008) (Lean et al., 1995). Body mass index (BMI) was defined as weight in kg divided by height in meters squared. Blood pressure $(\mathrm{mmHg})$ and heart rate were measured thrice on the left arm, with an appropriately sized cuff, after at least 10 minute rest in the seated position using an Omron ${ }^{\circledR}$ HEM-907 automated oscillometric sphygmomanometer (Matsusaka, Japan). The average of the last two measurements was used for analyses (Firmann et al., 2008). 


\section{Allostatic Load}

Constituting risk factors of $\mathrm{AL}$ are often analyzed in groups corresponding to five homeostatic systems or processes: cardiovascular system, metabolism, hypothalamic-pituitary-adrenal (HPA) axis, autonomic nervous system (ANS) and inflammation (Seeman et al., 2010). Two indices of AL were generated. The first "classic" index (AL1), described in eTable 1, was based on cardiovascular, metabolic, dyslipidemic and inflammatory markers. Compared to the markers usually included in the assessment of AL, we had to omit the neuroendocrine stress factors as they were not available in the CoLaus dataset. However, we distinguished a "lipids" dimension, usually integrated in "metabolism" (Seeman et al., 2010). The second "extended" index (AL2) additionally included markers of oxidative stress (eTable 1). We dichotomized the markers into high-risk versus low-risk (1-0) according to gender-specific quartiles. The high-risk quartile was the top quartile of all markers, with the exception of adiponectin and high-density lipoprotein cholesterol (HDL) (lowest quartile, eTable 1). The AL scores were then computed by summing the dichotomized values. In logistic regressions, AL1, AL2 and the five homeostatic dimensions were dichotomized using as a cut-off the value closest to the median (eTable 2). This latter analysis was chosen to provide a robust association metric that allow comparing the associations of high AL values with SES with those of high values for each dimension.

In total, we assessed nine new risk markers which were not included in previous studies: high leptin and low adiponectin (metabolism), high triglycerides and high apolipoprotein B (lipids), high interleukin 1-B and high tumor necrosis factor alpha (TNF- $\alpha$ ) (inflammation) and, finally, high uric acid, high homocysteine and high gamma-glutamyl transferase (gGT) were the markers constituting the new dimension of oxidative stress. Validity assessment analyses of the five dimensions of AL showed that although all dimensions were significantly interdependent, their non-parametric Spearman correlations were reasonably low (range 0.047 to 0.350 ). We thus considered the five dimensions as reasonably subdivided.

\section{Statistical analyses}

All analyses were conducted in Stata 12.1 (Stata Corp, College Station, Texas, USA) and were stratified by gender. In preliminary analysis, mean values of the two AL scores and of the five system components were calculated for each gender and socioeconomic category. Chi-squared test was used to examine differences in the distribution of socio-demographic 
and behavioral factors across categories of education and receiving social transfers. The association of education and receiving social transfers with physiological dysregulation scores was further explored with age-adjusted logistic regression for dichotomized scores (Model 1). After testing that the association between education and AL did not depart from a linear trend (all $p$ for departure from a linear trend $>0.05$ ), the four-level education variable was entered as a continuous variable in multivariable analyses. The odds ratio associated with a unit change in education was cubed to yield the odds ratio for the lowest versus the highest educational category. To assess the extent to which the two measures of SES were independently related to $\mathrm{AL}$ and the five systems components, we introduced in the regression models the alternative SES indicator and calculated a percent attenuation of the OR with the formula: \% attenuation=100* (OR Model $1_{\text {age-adjusted }}$ - OR Model $\left.2_{\text {Model1+ST or education }}\right) /($ OR Model 1 ageadjusted -1$)$.

We additionally assessed the extent to which health behaviors and marital status contributed to the association between SES indicators and AL by including them as covariates and then calculating the $\%$ attenuation as described above.

To investigate further the association between AL and SES without losing precision to dichotomization, quantile regressions were performed on the original AL scores using multivariable age-adjusted quantile regression for quasi-continuous dependent variables (AL1 and AL2 scores).

\section{RESULTS}

Of the 6184 participants of the CoLaus study, 1110 were excluded because in age of receiving retirement benefits, as described previously. Of the remaining 5074, we excluded 1485 participants for one or more of the following reasons: missing information on SES $(\mathrm{N}=25)$, missing data for at least one marker used to compute the AL $(\mathrm{N}=1384$, of which 454 for Interleukin-6, 495 for insulin and 326 for leptin), or missing data on other covariates $(\mathrm{N}=75)$, categories not mutually excluded. In total, 3589 individuals were included in the present study. Excluded participants were more frequently females (44\% vs. $39 \%, p<0.001$ ), were older (mean age 56 vs. 50 years, $\mathrm{p}<0.001$ ) and tended to have a more disadvantaged socioeconomic profile $(\mathrm{p}<0.001)$. 


\section{Sample characteristics}

The main characteristics of the sample according to gender and SES are summarized in Table 1. Men and women receiving ST had a lower educational attainment $(\mathrm{p}<0.001)$. In general, participants with low SES (either measured as low education or receiving social transfers) were more likely to follow unhealthy behaviors, although no significant difference was apparent for alcohol consumption. Figure 1 illustrates mean scores of AL1 and AL2 and of the five system components in men and in women, by ST status and educational category. AL1 and AL2 were significantly higher in individuals receiving ST and a dose-response relationship between allostatic load and education was observed $(\mathrm{p}<0.001)$.

\section{Social transfers and allostatic load}

Results from logistic regressions for the association of AL1, AL2 and the five composing systems with ST are presented in Table 2. Men receiving ST were more likely to have inflammatory $(\mathrm{OR}=1.30,95 \% \mathrm{CI}: 0.99 ; 1.71)$, cardiovascular $(\mathrm{OR}=1.31,95 \% \mathrm{CI}: 1.00 ; 1.71)$ and metabolic ( $\mathrm{OR}=1.67,95 \% \mathrm{CI}: 1.28 ; 2.20)$ dysregulation, higher oxidative stress $(\mathrm{OR}=1.28,95 \% \mathrm{CI}: 0.97 ; 1.78)$ as well as higher AL1 (OR=1.93,95\%CI:1.45;2.55) and AL2 $(\mathrm{OR}=1.83,95 \% \mathrm{CI}: 1.38 ; 2.41)$, although some of these associations were not significant at $\mathrm{p}=0.05$. Adjustment for education explained about $30 \%$ of the associations between ST and $\mathrm{AL} 1 / \mathrm{AL} 2$, but there remained a $\sim 60 \%$ increased risk of $\mathrm{AL}$ for men receiving vs. non receiving ST (OR=1.59, 95\%CI: 1.19;2.11 for AL2).

The association was also partially attenuated after adjustment for health behaviors and marital status. In women, receiving ST was associated with greater physiological dysregulation for all scores except for the cardiovascular component. The association between ST and AL was largely attenuated after adjustment for education (\% attenuation: 47\% for AL1 and 41\% for AL2), but the association between AL2 and ST remained statistically significant. Health behaviors and marital status did not contribute much to the association between ST and AL in women $(4 \%$ and $12 \%)$.

\section{Education and allostatic load}


Results for education are shown in Table 3. Education was strongly associated with dysregulation of the five homeostatic systems examined (with the exception of cardiovascular and oxidative stress component in women), the metabolic component in particular $(\mathrm{OR}=2.09 / 3.09$ for men/women). Participants with a low education were about 3 times more likely to have high levels of AL1 and AL2 than those with a high education (OR=3.24/3.04 for men/women for AL2). These associations were only slightly attenuated when controlling for ST. Control for health behaviors and marital status contributed to explain about $30 \%$ of the association between education and AL in men and about $20 \%$ in women. A strong doseresponse association was observed between the SES score and high AL1/AL2 (Figure 2).

In analyses using quantile regressions performed on the original AL scores, receiving ST and having a low educational attainment remained strongly associated with AL1 and AL2 in the fully adjusted models, for both genders (Table 4).

\section{Sensitivity Analyses}

In additional sensitivity analyses, we assessed whether there were interactive effects between education and social transfer on AL, but found no evidence for such effects (all p-values for interaction between education and receiving social transfers in relation to $\mathrm{AL}>0.05$ ).

\section{DISCUSSION}

In this study, we found strong and robust associations between SES and AL in adult men and women from a population-based study in Switzerland. The two indicators of SES used in this study, receiving social transfers and having a low education, independently and cumulatively predicted high AL and dysregulation of several homeostatic systems. Additionally, this study hints to the potentials of including markers of oxidative stress in computing allostatic load indexes.

The finding of an association between SES and AL is in line with previous research showing strong socioeconomic differences in physiological dysregulation (Dowd and Goldman, 2006; Gersten, 2008; Hu et al., 2007; Kubzansky et al., 1999; Seeman et al., 2008; Seeman et al., 2004). Multivariable analyses showed that this association was independent of age, health 
behaviors and marital status. Moreover, the two measures of SES independently predicted AL, suggesting that they capture different dimensions of SES, in line with previous studies (Geyer et al., 2006; Stringhini et al., 2011).

Previous studies had reported association between a variety of indicators of SES(Dowd et al., 2009), including education(Hu et al., 2007; Seeman et al., 2004), income (Hu et al., 2007) and socio-economic disadvantage(Gruenewald et al., 2012) with AL. This study points to an important link between receiving ST and health, and hints to the potentials of such a marker in predicting financial distress in studies conducted in high income countries, given the difficulty of collecting measures of income and wealth in epidemiological studies (Krieger et al., 1997). In particular, we might speculate that receiving ST captures aspects related to a stressful life (such as financial adversity) that might not be accounted for by education. On the other hand, the association of education with AL was only slightly attenuated by controlling for ST, implying residual confounding or that other aspects than economic resources might be implicated. For example, the strong association of education with AL might be related to the fact that 1) education, at least in Europe, strongly correlates with occupational position (Miech and Hauser, 2001), and people with low education might occupy jobs that are more stressful in their everyday life; 2) education is related to several aspects that might buffer the effect of chronic stress on health, such as social support, social relationships or better ability to cope with stressful situations (Seeman, 1996; Stringhini et al., 2012).

In our study, we used two measures of AL, one including markers typically assessed to compute the AL scores (with the exception of neuroendocrine markers), and a new score including six additional markers of metabolic dysregulation, inflammation and dyslipidemia, as well as a whole new component reflecting oxidative stress. We believe that the additional inclusion of these risk markers would be particularly helpful in future studies. For example, high gamma-glutamyl transferase (gGT) is a recognized risk factor for cardiovascular disease, the metabolic syndrome, and all-cause mortality, and is perceived as an important marker of oxidative stress (Mason et al., 2010). Although high gGT is strongly linked to metabolism, atherosclerosis and hepatic inflammation (Mason et al., 2010), we placed it into the component of "oxidative stress", in which we also included high serum uric acid and high homocysteine levels. Mechanisms by which low SES could lead to oxidative stress are via chronic stress-induced inflammation and/or anti-oxidant dysbalance (Devaki et al., 2013). To our knowledge, this is the first study to show an association between SES and oxidative stress 
in a population-based sample. Further research should assess whether it also strongly predicts adverse health outcomes.

Several pathways have been proposed to explain the higher burden of AL among the lower socioeconomic groups, and include psychological characteristics, coping strategies, social relationships and support, and health behaviors (Hawkley et al., 2011). In our study, health behaviors and marital status (a measure of social support) partly attenuated the association between SES and AL, but a large part remained unexplained. Other measures of social support, such as social networks or perceived support were not available in our study.

The association of SES with AL (and their components) seemed to differ in men and women. For example, receiving ST was associated with high oxidative stress in women but not in men while having a low education predicted higher oxidative stress in men but not in women. These results are consistent with previous findings showing important gender differences in the physiologic response to stress. For example, men show greater cortisol responses to stress than women (Chrousos, 2010; Heraclides et al., 2012; Kirschbaum et al., 1992; LipinskaGrobelny, 2011; Maestripieri et al., 2010; McEwen, 2010; Vassalle et al., 2011).

\section{Strengths and limitations}

The major strengths of this study are in the richness of available cardiometabolic phenotypes and its population-based nature. Moreover, the use of two indicators of SES allowed us to show how different dimensions of SES might relate to different aspects of Al. Finally, this is the first study to assess associations between SES and markers of oxidative stress.

This study also has some limitations. First, the new AL score needs to be validated in further studies. Also, the overall prevalence of receiving ST was high (16\%). This might be partly due to the ambiguity of the question on receiving "social help", which mentioned as examples of social help "[help] for the health insurance, retirement allocations or allocations for the invalids". In future work, it would be useful to have more precise information on the different types of financial compensation received, along with information on the amount of time over which they have been received. 
Further, reverse causation could also partly explain the association between ST and AL. This direction of causality should be further explored, for instance using genetic instrumental variables which could predict chronic stress. Finally, given the large number of associations explored, several covariates (i.e.: smoking, alcohol consumption and physical activity) were assessed as dichotomous variables and this might have lead to loss of precision. However, we repeated the analysis using finer categorizations for these variables and results did not vary.

\section{CONCLUSIONS}

In Switzerland, a high income European country with mandatory health insurance, men and women reporting to receive social transfers or with a low educational attainment had higher measured cumulative homeostatic dysregulation, independently of age, marital status, and health behaviors. These results are in line with previous results on North American populations. Moreover, we showed that the two measures of SES examined independently predicted higher levels of allostatic load, suggesting that multiple dimensions of SES contribute to engender a higher burden of allostatic load. This study is also one of the first to show that participants with low SES are at higher risk of oxidative stress, which may justify its inclusion as a separate component of allostatic load. 
ACKNOWLEDGEMENTS: The CoLaus study was supported by research grants from GlaxoSmithKline, the University Hospital Center, the Faculty of Biology and Medicine of Lausanne, Switzerland and the Swiss National Science Foundation (grant no: 33CSCO122661). The authors also express their gratitude to the participants in the Lausanne CoLaus study and to the investigators who have contributed to the recruitment, in particular Yolande Barreau, Anne-Lise Bastian, Binasa Ramic, Martine Moranville, Martine Baumer, Marcy Sagette, Jeanne Ecoffey and Sylvie Mermoud for data collection.

FUNDING: SS is supported by an Ambizione Grant ( ${ }^{\circ} \mathrm{PZO0P} 3$ 147998) from the Swiss National Science Foundation (SNSF) and was supported by a fellowship of the Swiss School of Public Health (SSPH+) during the preparation of this manuscript. The CoLaus study was supported by research grants from GlaxoSmithKline, the University Hospital Center, the Faculty of Biology and Medicine of Lausanne, Switzerland and the Swiss National Science Foundation (grant no: 33CSCO-122661).

FINANCIAL DISCLOSURE: The funders had no role in study design, data collection and analysis, decision to publish, or preparation of the manuscript.

CONFLICT OF INTEREST STATEMENT: The Authors declare that there is no conflict of interest. 
Table 1. Characteristics of men ( $\mathrm{N}=1777)$ and women ( $=1812)$ included in the study by socioeconomic indicators, Colaus Study (Lausanne, Switzerland, 2003-2006)

\begin{tabular}{|c|c|c|c|c|c|c|c|c|c|c|c|c|c|c|c|c|}
\hline & \multicolumn{8}{|c|}{ MEN } & \multicolumn{8}{|c|}{ WOMEN } \\
\hline & \multicolumn{4}{|c|}{ Social transfers } & \multicolumn{4}{|c|}{ Educational attainment } & \multicolumn{4}{|c|}{ Social transfers } & \multicolumn{4}{|c|}{ Educational attainment } \\
\hline & $\begin{array}{c}\text { Yes } \\
(N=256)\end{array}$ & $\begin{array}{c}\text { No } \\
(N=1521)\end{array}$ & $\%$ ST & $P^{a}$ & $\begin{array}{l}\text { Low } \\
(\mathrm{N}=941)\end{array}$ & $\begin{array}{l}\text { High } \\
(\mathrm{N}=836)\end{array}$ & $\%$ Low & $P^{a}$ & $\begin{array}{c}\text { Yes } \\
(N=317)\end{array}$ & $\begin{array}{c}\text { No } \\
(N=1495)\end{array}$ & $\%$ ST & $P^{a}$ & $\begin{array}{c}\text { Low } \\
(N=1054)\end{array}$ & $\begin{array}{l}\text { High } \\
(N=758)\end{array}$ & $\%$ Low & $P^{a}$ \\
\hline Age, Mean (SD, years) & $\begin{array}{c}52.0 \\
( \pm 8.7)\end{array}$ & $\begin{array}{c}50.0 \\
( \pm 8.5)\end{array}$ & NA & & $\begin{array}{c}50.7 \\
( \pm 8.6)\end{array}$ & $\begin{array}{c}49.7 \\
( \pm 8.5)\end{array}$ & NA & & $\begin{array}{c}49.4 \\
( \pm 8.0)\end{array}$ & $\begin{array}{c}51.1 \\
( \pm 8.8)\end{array}$ & NA & & $\begin{array}{c}50.5 \\
( \pm 8.1)\end{array}$ & $\begin{array}{c}48.5 \\
( \pm 8.3)\end{array}$ & NA & \\
\hline Social transfers & & & & NA & & & & $<0.001$ & & & & NA & & & & $<0.001$ \\
\hline Yes & NA & NA & NA & & 191 & 65 & $74.6 \%$ & & NA & NA & NA & & 817 & 678 & $54.7 \%$ & \\
\hline No & NA & NA & NA & & 750 & 771 & $49.3 \%$ & & NA & NA & NA & & 237 & 80 & $74.8 \%$ & \\
\hline Educational Attainment & & & & $<0.001$ & & & & NA & & & & $<0.001$ & & & & NA \\
\hline Primary & 74 & 214 & $25.7 \%$ & & NA & NA & NA & & 276 & 117 & $29.8 \%$ & & NA & NA & NA & \\
\hline Apprenticeship & 117 & 536 & $17.9 \%$ & & NA & NA & NA & & 541 & 120 & $18.2 \%$ & & NA & NA & NA & \\
\hline High school/college & 36 & 377 & $8.7 \%$ & & NA & NA & NA & & 401 & 59 & $12.8 \%$ & & NA & NA & NA & \\
\hline University & 29 & 394 & $6.9 \%$ & & NA & NA & NA & & 277 & 21 & $7.0 \%$ & & NA & NA & NA & \\
\hline Marital Status & & & & 0.142 & & & & 0.018 & & & & $<0.001$ & & & & $<0.001$ \\
\hline Single & 39 & 235 & $14.2 \%$ & & 121 & 153 & $44.2 \%$ & & 276 & 54 & $16.4 \%$ & & 162 & 168 & $49.1 \%$ & \\
\hline Married & 158 & 1017 & $13.4 \%$ & & 640 & 535 & $54.5 \%$ & & 855 & 115 & $11.9 \%$ & & 589 & 381 & $60.7 \%$ & \\
\hline Divorced & 54 & 254 & $17.5 \%$ & & 169 & 139 & $54.9 \%$ & & 325 & 115 & $26.1 \%$ & & 252 & 188 & $57.3 \%$ & \\
\hline Midow & 5 & 15 & $25.0 \%$ & & 11 & 9 & $55.0 \%$ & & 39 & 33 & $45.8 \%$ & & 51 & 21 & $70.8 \%$ & \\
\hline Smoking & & & & 0.001 & & & & $<0.001$ & & & & 0.010 & & & & 0.242 \\
\hline No & 158 & 1100 & $12.6 \%$ & & 631 & 627 & $50.2 \%$ & & 1114 & 213 & $16.1 \%$ & & 761 & 566 & $57.4 \%$ & \\
\hline Yes & 98 & 421 & $18.9 \%$ & & 310 & 209 & $59.7 \%$ & & 381 & 104 & $21.4 \%$ & & 293 & 192 & $60.4 \%$ & \\
\hline Alcohol consumption & & & & 0.433 & & & & $<0.001$ & & & & 0.933 & & & & 0.822 \\
\hline No & 167 & 1030 & $14.0 \%$ & & 583 & 614 & $48.7 \%$ & & 1318 & 280 & $17.5 \%$ & & 928 & 670 & $58.1 \%$ & \\
\hline Yes & 89 & 491 & $15.3 \%$ & & 538 & 222 & $61.7 \%$ & & 177 & 37 & $17.3 \%$ & & 126 & 88 & $58.9 \%$ & \\
\hline Physical activity & & & & $<0.001$ & & & & $<0.001$ & & & & $<0.001$ & & & & $<0.001$ \\
\hline Never & 134 & 524 & $20.4 \%$ & & 456 & 202 & $69.3 \%$ & & 490 & 138 & $22.0 \%$ & & 444 & 184 & $70.7 \%$ & \\
\hline Once a week & 122 & 997 & $10.9 \%$ & & 485 & 634 & $43.3 \%$ & & 1005 & 179 & $15.1 \%$ & & 610 & 574 & $51.5 \%$ & \\
\hline
\end{tabular}

SD: Standard Deviation; ST: Social transfers.
${ }^{a}$ P value for difference by ST or education from Chi-squared test. 
Table 2. Association of receiving social transfers with dichotomized allostatic loads and five system components, Colaus Study (Lausanne, Switzerland, 2003-2006)

\begin{tabular}{|c|c|c|c|c|c|c|c|c|}
\hline & \multicolumn{2}{|c|}{ Model 1: age-adjusted } & \multicolumn{3}{|c|}{ Model 1 + education } & \multicolumn{3}{|c|}{$\begin{array}{c}\text { Model 1+ health behaviors }{ }^{\mathrm{a}} \& \\
\text { marital status }\end{array}$} \\
\hline & $\mathrm{OR}^{\mathrm{b}}$ & $95 \% \mathrm{Cl}$ & $\mathrm{OR}^{\mathrm{b}}$ & $95 \% \mathrm{Cl}$ & $\% \Delta^{c}$ & $\mathrm{OR}^{\mathrm{b}}$ & $95 \% \mathrm{Cl}$ & $\% \Delta^{c}$ \\
\hline \multicolumn{9}{|l|}{ Men } \\
\hline Inflammation & 1.30 & $(0.99 ; 1.71)$ & 1.22 & $(0.92 ; 1.62)$ & NA & 1.22 & $(0.92 ; 1.62)$ & NA \\
\hline Cardiovascular & 1.31 & $(1.00 ; 1.71)$ & 1.19 & $(0.91 ; 1.57)$ & $-39 \%$ & 1.21 & $(0.92 ; 1.59)$ & $-32 \%$ \\
\hline Lipidemia & 1.09 & $(0.82 ; 1.44)$ & 0.97 & $(0.73 ; 1.29)$ & NA & 0.99 & $(0.75 ; 1.32)$ & NA \\
\hline Metabolic & 1.67 & $(1.28 ; 2.20)$ & 1.43 & $(1.09 ; 1.89)$ & $-36 \%$ & 1.49 & $(1.13 ; 1.97)$ & $-27 \%$ \\
\hline Oxidative stress & 1.28 & $(0.97 ; 1.68)$ & 1.17 & $(0.88 ; 1.54)$ & NA & 1.18 & $(0.89 ; 1.56)$ & NA \\
\hline Allostatic Load 1 & 1.93 & $(1.45 ; 2.55)$ & 1.62 & $(1.21 ; 2.15)$ & $-33 \%$ & 1.67 & $(1.25 ; 2.23)$ & $-28 \%$ \\
\hline Allostatic Load 2 & 1.83 & $(1.38 ; 2.41)$ & 1.52 & $(1.14 ; 2.02)$ & $-37 \%$ & 1.59 & $(1.19 ; 2.11)$ & $-29 \%$ \\
\hline \multicolumn{9}{|l|}{ Women } \\
\hline Inflammation & 1.33 & $(1.03 ; 1.71)$ & 1.20 & $(0.93 ; 1.56)$ & $-39 \%$ & 1.36 & $(1.04 ; 1.76)$ & $9 \%$ \\
\hline Cardiovascular & 0.97 & $(0.76 ; 1.25)$ & 0.94 & $(0.73 ; 1.20)$ & NA & 1.00 & $(0.77 ; 1.29)$ & NA \\
\hline Lipidemia & 1.62 & $(1.23 ; 2.12)$ & 1.47 & $(1.12 ; 1.94)$ & $-24 \%$ & 1.48 & $(1.12 ; 1.96)$ & $-23 \%$ \\
\hline Metabolic & 1.64 & $(1.28 ; 2.10)$ & 1.40 & $(1.09 ; 1.81)$ & $-38 \%$ & 1.63 & $(1.26 ; 2.11)$ & $-2 \%$ \\
\hline Oxidative stress & 1.61 & $(1.25 ; 2.08)$ & 1.57 & $(1.21 ; 2.04)$ & $-7 \%$ & 1.49 & $(1.14 ; 1.93)$ & $-20 \%$ \\
\hline Allostatic Load 1 & 1.45 & $(1.13 ; 1.87)$ & 1.24 & $(0.95 ; 1.60)$ & $-47 \%$ & 1.43 & $(1.10 ; 1.85)$ & $-4 \%$ \\
\hline Allostatic Load 2 & 1.59 & $(1.23 ; 2.05)$ & 1.35 & $(1.04 ; 1.75)$ & $-41 \%$ & 1.52 & $(1.17 ; 1.99)$ & $-12 \%$ \\
\hline
\end{tabular}

$\mathrm{Cl}$ : 95\% Confidence Interval; NA: not applicable (percent attenuations were calculated only if there was a significant association); OR: Odds ratio; $\Delta$ : Attenuation.

${ }^{\text {a }}$ Smoking, alcohol consumption, physical activity.

${ }^{b}$ Odds ratio for receiving versus non-receiving social transfers.

${ }^{c}$ Percent attenuation of the OR in Model 1 after inclusion of the variable in question. 
Table 3. Association of education ${ }^{\text {a }}$ with dichotomized allostatic loads and five system components, Colaus Study (Lausanne, Switzerland, 2003-2006)

\begin{tabular}{|c|c|c|c|c|c|c|c|c|}
\hline & \multicolumn{2}{|c|}{ Model 1: age-adjusted } & \multicolumn{3}{|c|}{ Model 1 + ST } & \multicolumn{3}{|c|}{$\begin{array}{c}\text { Model 1+ health behaviors }{ }^{\mathrm{b}} \& \\
\text { marital status }\end{array}$} \\
\hline & $\mathrm{OR}^{\mathrm{c}}$ & $95 \% \mathrm{Cl}$ & $\mathrm{OR}^{\mathrm{c}}$ & $95 \% \mathrm{Cl}$ & $\% \Delta^{\mathrm{d}}$ & $\mathrm{OR}^{\mathrm{c}}$ & $95 \% \mathrm{Cl}$ & $\% \Delta^{\mathrm{d}}$ \\
\hline \multicolumn{9}{|l|}{$\overline{M e n}$} \\
\hline Inflammation & 1.46 & $(1.11 ; 1.93)$ & 1.41 & $(1.06 ; 1.86)$ & $-11 \%$ & 1.45 & $(1.08 ; 1.94)$ & $-2 \%$ \\
\hline Cardiovascular & 1.76 & $(1.33 ; 2.33)$ & 1.71 & $(1.28 ; 2.27)$ & $-7 \%$ & 1.51 & $(1.12 ; 2.03)$ & $-33 \%$ \\
\hline Lipidemia & 1.87 & $(1.41 ; 2.49)$ & 1.88 & $(1.41 ; 2.52)$ & $1 \%$ & 1.63 & $(1.20 ; 2.20)$ & $-28 \%$ \\
\hline Metabolic & 2.68 & $(2.00 ; 3.59)$ & 2.50 & $(1.86 ; 3.37)$ & $-11 \%$ & 2.19 & $(1.61 ; 2.99)$ & $-29 \%$ \\
\hline Oxidative stress & 1.71 & $(1.29 ; 2.26)$ & 1.66 & $(1.25 ; 2.21)$ & $-7 \%$ & 1.44 & $(1.07 ; 1.94)$ & $-38 \%$ \\
\hline Allostatic Load 1 & 3.12 & $(2.34 ; 4.17)$ & 2.87 & $(2.14 ; 3.85)$ & $-12 \%$ & 2.51 & $(1.84 ; 3.41)$ & $-29 \%$ \\
\hline Allostatic Load 2 & 3.24 & $(2.43 ; 4.33)$ & 3.02 & $(2.24 ; 4.04)$ & $-10 \%$ & 2.53 & $(1.87 ; 3.43)$ & $-32 \%$ \\
\hline \multicolumn{9}{|l|}{ Women } \\
\hline Inflammation & 1.92 & $(1.44 ; 2.56)$ & 1.85 & $(1.38 ; 2.47)$ & $-8 \%$ & 1.78 & $(1.32 ; 2.40)$ & $-15 \%$ \\
\hline Cardiovascular & 1.26 & $(0.95 ; 1.68)$ & 1.28 & $(0.96 ; 1.71)$ & NA & 1.19 & $(0.89 ; 1.61)$ & NA \\
\hline Lipidemia & 1.87 & $(1.39 ; 2.51)$ & 1.73 & $(1.28 ; 2.33)$ & $-16 \%$ & 1.73 & $(1.27 ; 2.35)$ & $-16 \%$ \\
\hline Metabolic & 3.09 & $(2.29 ; 4.19)$ & 2.89 & $(2.12 ; 3.92)$ & $-10 \%$ & 2.63 & $(1.92 ; 3.60)$ & $-22 \%$ \\
\hline Oxidative stress & 1.26 & $(0.94 ; 1.68)$ & 1.14 & $(0.85 ; 1.53)$ & NA & 1.15 & $(0.85 ; 1.55)$ & NA \\
\hline Allostatic Load 1 & 2.88 & $(2.14 ; 3.88)$ & 2.76 & $(2.04 ; 3.73)$ & $-6 \%$ & 2.50 & $(1.83 ; 3.40)$ & $-20 \%$ \\
\hline Allostatic Load 2 & 3.04 & $(2.26 ; 4.10)$ & 2.86 & $(2.12 ; 3.87)$ & $-9 \%$ & 2.65 & $(1.94 ; 3.61)$ & $-19 \%$ \\
\hline
\end{tabular}

Cl: 95\% Confidence Interval; NA: not applicable (percent attenuations were calculated only if there was a significant association); OR: Odds ratio; ST: Social transfers; $\Delta$ : Attenuation.

${ }^{a}$ Education (4-level categorical variable) is entered as a continuous variable.

${ }^{\mathrm{b}}$ Smoking, alcohol consumption, physical activity.

${ }^{c}$ Odds ratio for lowest versus highest educational category.

${ }^{\mathrm{d}}$ Percent attenuation of the OR in Model 1 after inclusion of the variable in question. 
Table 4 Association of receiving social transfers and education ${ }^{\mathrm{b}}$ with continuous allostatic load scores, Colaus Study (Lausanne, Switzerland, 2003-2006)

\begin{tabular}{|c|c|c|c|c|c|c|c|c|c|}
\hline \multirow[b]{4}{*}{ Men } & \multicolumn{9}{|c|}{ Social transfers } \\
\hline & \multicolumn{3}{|c|}{ Model 1: age-adjusted } & \multicolumn{3}{|c|}{ Model 1 + education } & \multicolumn{3}{|c|}{$\begin{array}{c}\text { Model 1+ health } \\
\text { behaviors } \& \text { marital } \\
\text { status }\end{array}$} \\
\hline & $\beta$ & SE & $\mathbf{P}$ & $\beta$ & SE & $\mathbf{P}$ & $\beta$ & SE & $\mathbf{P}$ \\
\hline & & & & & & & & & \\
\hline Allostatic Load $1[0 ; 11]$ & 0.90 & 0.16 & $<0.001$ & 0.73 & 0.18 & $<0.001$ & 0.42 & 0.19 & 0.022 \\
\hline Allostatic Load $2[0 ; 20]$ & 1.43 & 0.30 & $<0.001$ & 1.03 & 0.28 & $<0.001$ & 0.88 & 0.34 & 0.010 \\
\hline \multicolumn{10}{|l|}{ Women } \\
\hline Allostatic Load $1[0 ; 11]$ & 0.61 & 0.16 & $<0.001$ & 0.38 & 0.16 & 0.017 & 0.66 & 0.13 & $<0.001$ \\
\hline \multirow[t]{4}{*}{ Allostatic Load $2[0 ; 20]$} & 0.90 & 0.24 & $<0.001$ & 0.60 & 0.23 & 0.010 & 0.70 & 0.23 & 0.003 \\
\hline & \multicolumn{9}{|c|}{ Educational attainment } \\
\hline & \multicolumn{3}{|c|}{ Model 1: age-adjusted } & \multicolumn{3}{|c|}{ Model 1 + ST } & \multicolumn{3}{|c|}{$\begin{array}{c}\text { Model 1+ health } \\
\text { behaviorsa \& marital } \\
\text { status }\end{array}$} \\
\hline & $\beta$ & SE & $\mathbf{P}$ & $\beta$ & SE & $\mathbf{P}$ & $\beta$ & SE & $\mathbf{P}$ \\
\hline \multicolumn{10}{|l|}{ Men } \\
\hline Allostatic Load $1[0 ; 11]$ & 1.37 & 0.18 & $<0.001$ & 1.23 & 0.19 & $<0.001$ & 0.92 & 0.19 & $<0.001$ \\
\hline Allostatic Load $2[0 ; 20]$ & 1.97 & 0.29 & $<0.001$ & 1.83 & 0.26 & $<0.001$ & 1.28 & 0.31 & $<0.001$ \\
\hline \multicolumn{10}{|l|}{ Women } \\
\hline Allostatic Load $1[0 ; 11]$ & 1.17 & 0.17 & $<0.001$ & 1.10 & 0.18 & $<0.001$ & 0.93 & 0.18 & $<0.001$ \\
\hline Allostatic Load $2[0 ; 20]$ & 1.73 & 0.26 & $<0.001$ & 1.67 & 0.27 & $<0.001$ & 1.36 & 0.26 & $<0.001$ \\
\hline
\end{tabular}


Figure 1. Mean score of allostatic loads and their components by gender and socioeconomic indicator, Colaus Study (Lausanne, Switzerland, 2003-2006)

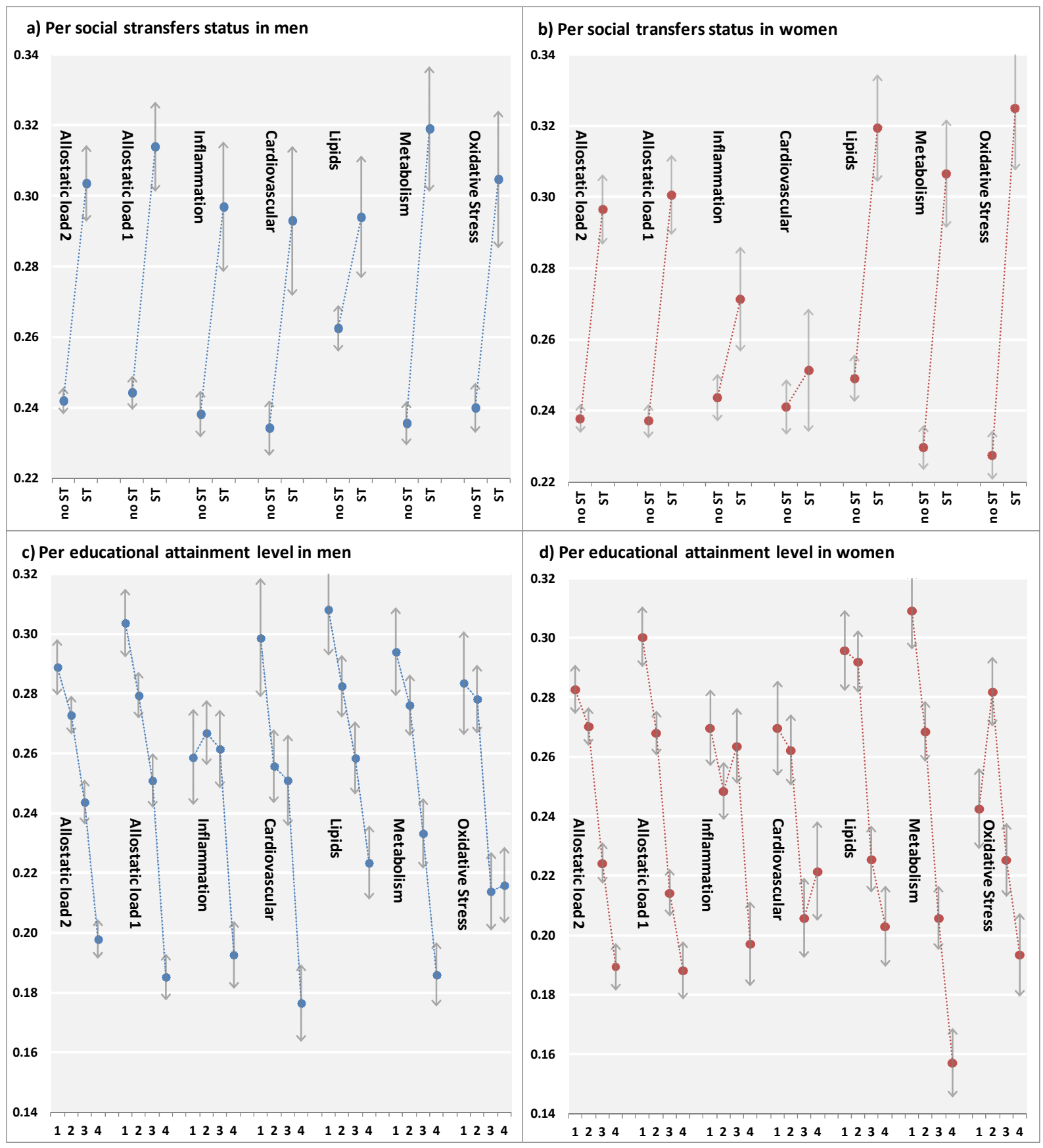

SD: Standard deviation; ST: Social transfers. Education is classified as (1) Primary education (2) Vocational secondary education (3) Secondary education (4) University.education 
Figure 2. Association of a composite socioeconomic score with allostatic load (AL1 and AL2), Colaus Study (Lausanne, Switzerland, 2003-2006)

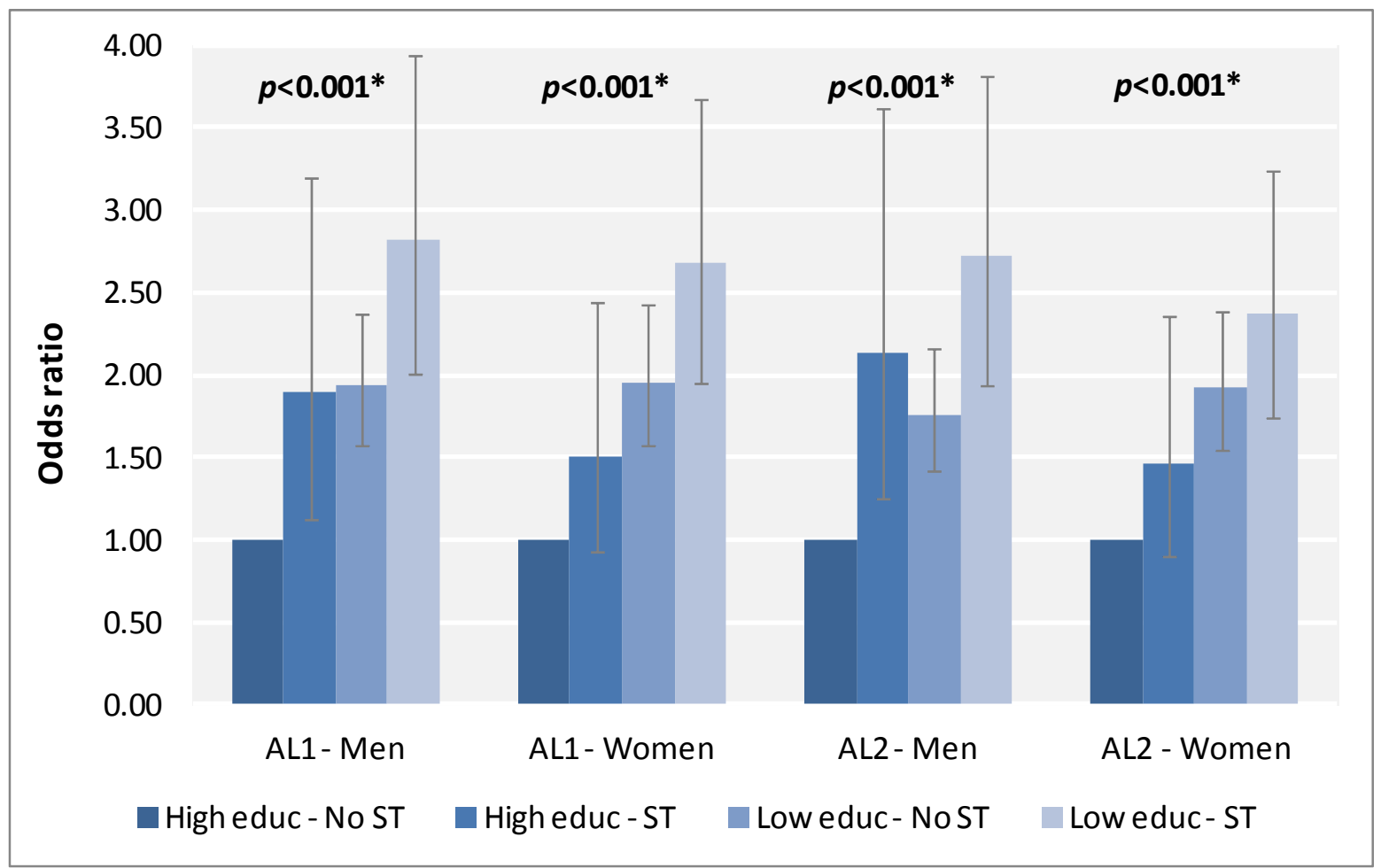

AL: Allostatic Load; educ: education; ST: Social transfers.

"Low education" includes primary and vocational secondary education and "high education" includes secondary and university education.

* P-value for linear trend across SES score categories 
eTable 1. Components of classic (AL1) and extended (AL2) allostatic loads, Colaus Study (Lausanne, Switzerland, 2003-2006)

\begin{tabular}{|c|c|c|c|c|}
\hline Homeostatic System** & Component (Risk Factor) & Risk quartile & AL1 & AL2 \\
\hline \multicolumn{5}{|l|}{ Cardiovascular system } \\
\hline & Systolic blood pressure $(\mathrm{mm} \mathrm{Hg})$ & top & $x$ & $x$ \\
\hline & Diastolic blood pressure $(\mathrm{mm} \mathrm{Hg})$ & top & $x$ & $x$ \\
\hline & Heart rate (BPM) & top & $x$ & $x$ \\
\hline \multicolumn{5}{|l|}{ Metabolism } \\
\hline & Insulin (microlU/mL) & top & $x$ & $x$ \\
\hline & Glucose (mmol/l) & top & $x$ & $x$ \\
\hline & Body mass index (kg/m²) & top & $x$ & $x$ \\
\hline & Waist-to-hip ratio (cm) & top & $x$ & $x$ \\
\hline & Leptin* (ng/mL) & top & & $x$ \\
\hline & Adiponectin* (ng/mL) & bottom & & $x$ \\
\hline \multicolumn{5}{|l|}{ Lipids } \\
\hline & HDL cholesterol (mmol/l) & bottom & $x$ & $x$ \\
\hline & Total cholesterol (mmol/l) & top & $x$ & $x$ \\
\hline & Tryglycerides* (mmol//) & top & & $x$ \\
\hline & Apolipoprotein $B^{\star}$ (mg/dL) & top & & $x$ \\
\hline \multicolumn{5}{|l|}{ Inflammation } \\
\hline & C-reactive protein (mg/l) & top & $x$ & $x$ \\
\hline & Interleukin-6 (pg/ml) & top & $x$ & $x$ \\
\hline & Interleukin-1B* (pg/ml) & top & & $x$ \\
\hline & Tumor-necrosis factor alpha* $(\mathrm{pg} / \mathrm{ml})$ & top & & $x$ \\
\hline \multicolumn{5}{|c|}{ Oxidative Stress (in serum) } \\
\hline & Uric acid* $(\mu \mathrm{mol} / \mathrm{l})$ & top & & $x$ \\
\hline & Homocysteine $^{*}(\mu \mathrm{mol} / \mathrm{l})$ & top & & $x$ \\
\hline & Gamma-glutamyl transferase* (mmol/l) & top & & $x$ \\
\hline
\end{tabular}

*Nine extra components included in AL2. **Parameters for the hypothalamic-pituitary-adrenal (HPA) axis and the autonomic nervous system (ANS) could not be included in AL1 or AL2, since data was not available. 
eTable 2. Dichotomisation of scores by proximity to the median, Colaus Study (Lausanne, Switzerland, 2003-2006)

\begin{tabular}{|c|c|c|c|c|c|c|c|c|c|}
\hline \multirow[b]{2}{*}{ Score } & \multicolumn{7}{|c|}{ Number of observations and cumulative frequencies } & \multicolumn{2}{|c|}{ Dichotomisation } \\
\hline & 0 & 1 & 2 & 3 & 4 & 5 & 6 & $\begin{array}{c}\text { Group } \\
1 \\
\end{array}$ & $\begin{array}{c}\text { Group } \\
2\end{array}$ \\
\hline \multirow[t]{2}{*}{ Inflammation $[0 ; 4]$} & 1486 & 1102 & 607 & 322 & 66 & - & - & 0 & $1-4$ \\
\hline & $41.47 \%$ & $72.23 \%$ & $89.17 \%$ & $98.16 \%$ & $100 \%$ & & & & \\
\hline \multirow[t]{2}{*}{ Cardiovascular $[0 ; 3]$} & 1929 & 905 & 533 & 216 & & - & - & 0 & $1-3$ \\
\hline & $53.84 \%$ & $79.10 \%$ & $93.97 \%$ & $100 \%$ & & & & & \\
\hline \multirow[t]{2}{*}{ Lipids $[0 ; 4]$} & 1310 & 1218 & 689 & 275 & 91 & - & - & 0 & $1-4$ \\
\hline & $36.56 \%$ & $70.56 \%$ & $89.79 \%$ & $97.46 \%$ & $100 \%$ & & & & \\
\hline \multirow[t]{2}{*}{ Metabolic $[0 ; 6]$} & 1181 & 1017 & 561 & 385 & 253 & 149 & 37 & $0-1$ & $2-6$ \\
\hline & $32.96 \%$ & $61.35 \%$ & $77 \%$ & $87.75 \%$ & $94.81 \%$ & $98.97 \%$ & $100 \%$ & & \\
\hline \multirow[t]{3}{*}{ Oxidative stress $[0 ; 3]$} & 1724 & 1205 & 513 & 141 & & - & - & 0 & $1-3$ \\
\hline & $48.12 \%$ & $12.45 \%$ & $96.06 \%$ & $100 \%$ & & & & & \\
\hline & 0 & 1 & 2 & 3 & 4 & 5 & $\geq 6$ & & \\
\hline \multirow[t]{2}{*}{ AL1 $[0 ; 11]$} & 450 & 746 & 686 & 537 & 441 & 280 & $\ldots$ & $0-2$ & $3-11$ \\
\hline & $12.56 \%$ & $33.38 \%$ & $52.53 \%$ & $67.51 \%$ & $79.82 \%$ & $87.64 \%$ & & & \\
\hline \multirow[t]{2}{*}{ AL2 [0;20] } & 118 & 328 & 460 & 456 & 470 & 379 & $\ldots$ & $0-4$ & $5-20$ \\
\hline & $3.29 \%$ & & $25.29 \%$ & $38.01 \%$ & $51.13 \%$ & $61.71 \%$ & & & \\
\hline
\end{tabular}

Descriptions of classic (AL1) and extended (AL2) and allostatic loads only go up to 5, for readability. Scores closest to median (upper limit of "group 1") are marked in bold. 


\section{Reference List}

Adler, N.E., Boyce, T., Chesney, M.A., Cohen, S., Folkman, S., Kahn, R.L., Syme, S.L., 1994. Socioeconomic status and health. The challenge of the gradient. Am Psychol 49:15-24. Bopp, M., Minder, C.E., 2003. Mortality by education in German speaking Switzerland, 1990-1997: results from the Swiss National Cohort. Int J Epidemiol 32:346-54.

Chrousos, G.P., 2010. Stress and sex versus immunity and inflammation. Science signaling 3:pe36.

Crimmins, E.M., Johnston, M., Hayward, M., Seeman, T., 2003. Age differences in allostatic load: an index of physiological dysregulation. Exp Gerontol 38:731-4.

Devaki, M., Nirupama, R., Yajurvedi, H.N., 2013. Chronic stress-induced oxidative damage and hyperlipidemia are accompanied by atherosclerotic development in rats. Stress 16:233-43. Dowd, J.B., Goldman, N., 2006. Do biomarkers of stress mediate the relation between socioeconomic status and health? J Epidemiol Community Health 60:633-9.

Dowd, J.B., Simanek, A.M., Aiello, A.E., 2009. Socio-economic status, cortisol and allostatic load: a review of the literature. Int J Epidemiol 38:1297-309.

Evans, G.W., Kantrowitz, E., 2002. Socioeconomic status and health: the potential role of environmental risk exposure. Annu Rev Public Health 23:303-31.

Firmann, M., Mayor, V., Vidal, P.M., Bochud, M., Pecoud, A., Hayoz, D., Paccaud, F., Preisig, M., Song, K.S., et al., 2008. The CoLaus study: a population-based study to investigate the epidemiology and genetic determinants of cardiovascular risk factors and metabolic syndrome. BMC Cardiovasc Disord 8:6.

Forastiere, F., Stafoggia, M., Tasco, C., Picciotto, S., Agabiti, N., Cesaroni, G., Perucci, C.A., 2007. Socioeconomic status, particulate air pollution, and daily mortality: differential exposure or differential susceptibility. Am J Ind Med 50:208-16. 
Gallo, L.C., Jimenez, J.A., Shivpuri, S., Espinosa de los Monteros, K., Mills, P.J., 2011. Domains of chronic stress, lifestyle factors, and allostatic load in middle-aged MexicanAmerican women. Ann Behav Med 41:21-31.

Gersten, O., 2008. Neuroendocrine biomarkers, social relations, and the cumulative costs of stress in Taiwan. Soc Sci Med 66:507-19; discussion 20-35.

Geyer, S., Hemstrom, O., Peter, R., Vagero, D., 2006. Education, income, and occupational class cannot be used interchangeably in social epidemiology. Empirical evidence against a common practice. J Epidemiol Community Health 60:804-10.

Gruenewald, T.L., Karlamangla, A.S., Hu, P., Stein-Merkin, S., Crandall, C., Koretz, B., Seeman, T.E., 2012. History of socioeconomic disadvantage and allostatic load in later life. Soc Sci Med 74:75-83.

Hawkley, L.C., Lavelle, L.A., Berntson, G.G., Cacioppo, J.T., 2011. Mediators of the relationship between socioeconomic status and allostatic load in the Chicago Health, Aging, and Social Relations Study (CHASRS). Psychophysiology 48:1134-45.

Heraclides, A.M., Chandola, T., Witte, D.R., Brunner, E.J., 2012. Work stress, obesity and the risk of type 2 diabetes: gender-specific bidirectional effect in the Whitehall II study. Obesity (Silver Spring) 20:428-33.

Hertzman, C., 1999. The biological embedding of early experience and its effects on health in adulthood. Ann N Y Acad Sci 896:85-95.

Hertzman, C., Boyce, T., 2010. How experience gets under the skin to create gradients in developmental health. Annu Rev Public Health 31:329-47 3p following 47.

Hu, P., Wagle, N., Goldman, N., Weinstein, M., Seeman, T.E., 2007. The associations between socioeconomic status, allostatic load and measures of health in older Taiwanese persons: Taiwan social environment and biomarkers of aging study. J Biosoc Sci 39:545-56. 
Juster, R.P., McEwen, B.S., Lupien, S.J., 2010. Allostatic load biomarkers of chronic stress and impact on health and cognition. Neurosci Biobehav Rev 35:2-16.

Juster, R.P., Sindi, S., Marin, M.F., Perna, A., Hashemi, A., Pruessner, J.C., Lupien, S.J., 2011. A clinical allostatic load index is associated with burnout symptoms and hypocortisolemic profiles in healthy workers. Psychoneuroendocrinology 36:797-805. Kirschbaum, C., Wust, S., Hellhammer, D., 1992. Consistent sex differences in cortisol responses to psychological stress. Psychosom Med 54:648-57.

Krieger, N., Williams, D.R., Moss, N.E., 1997. Measuring social class in US public health research: concepts, methodologies, and guidelines. Annu Rev Public Health 18:341-78. Kristenson, M., Eriksen, H.R., Sluiter, J.K., Starke, D., Ursin, H., 2004. Psychobiological mechanisms of socioeconomic differences in health. Soc Sci Med 58:1511-22.

Kubzansky, L.D., Kawachi, I., Sparrow, D., 1999. Socioeconomic status, hostility, and risk factor clustering in the Normative Aging Study: any help from the concept of allostatic load? Ann Behav Med 21:330-8.

Lean, M.E., Han, T.S., Morrison, C.E., 1995. Waist circumference as a measure for indicating need for weight management. BMJ 311:158-61.

Lee, D.H., Blomhoff, R., Jacobs, D.R., Jr., 2004. Is serum gamma glutamyltransferase a marker of oxidative stress? Free Radic Res 38:535-9.

Lipinska-Grobelny, A., 2011. Effects of gender role on personal resources and coping with stress. Int J Occup Med Environ Health 24:18-28.

Liu, H.H., Shih, T.S., Huang, H.R., Huang, S.C., Lee, L.H., Huang, Y.C., 2013. Plasma homocysteine is associated with increased oxidative stress and antioxidant enzyme activity in welders. ScientificWorldJournal 2013:370487. 
Maestripieri, D., Baran, N.M., Sapienza, P., Zingales, L., 2010. Between- and within-sex variation in hormonal responses to psychological stress in a large sample of college students. Stress 13:413-24.

Marmot, M.G., Wilkinson, R.G., 2006. Social determinants of health, 2nd ed. Oxford University Press, Oxford; New York.

Mason, J.E., Starke, R.D., Van Kirk, J.E., 2010. Gamma-glutamyl transferase: a novel cardiovascular risk biomarker. Prev Cardiol 13:36-41.

McCartney, D., Scarborough, P., Webster, P., Rayner, M., 2012. Trends in social inequalities for premature coronary heart disease mortality in Great Britain, 1994-2008: a time trend ecological study. BMJ Open 2.

McEwen, B.S., 1998. Stress, adaptation, and disease. Allostasis and allostatic load. Ann N Y Acad Sci 840:33-44.

McEwen, B.S., 2004. Protection and damage from acute and chronic stress: allostasis and allostatic overload and relevance to the pathophysiology of psychiatric disorders. Ann N Y Acad Sci 1032:1-7.

McEwen, B.S., 2010. Stress, sex, and neural adaptation to a changing environment: mechanisms of neuronal remodeling. Ann N Y Acad Sci 1204 Suppl:E38-59.

McEwen, B.S., Stellar, E., 1993. Stress and the individual. Mechanisms leading to disease. Arch Intern Med 153:2093-101.

Miech, R.A., Hauser, R.M., 2001. Socioeconomic status and health at midlife. A comparison of educational attainment with occupation-based indicators. Ann Epidemiol 11:75-84. Pearlin, L.I., Schieman, S., Fazio, E.M., Meersman, S.C., 2005. Stress, health, and the life course: some conceptual perspectives. J Health Soc Behav 46:205-19. 
Seeman, T., Epel, E., Gruenewald, T., Karlamangla, A., McEwen, B.S., 2010. Socioeconomic differentials in peripheral biology: cumulative allostatic load. Ann N Y Acad Sci 1186:223-39.

Seeman, T., Merkin, S.S., Crimmins, E., Koretz, B., Charette, S., Karlamangla, A., 2008. Education, income and ethnic differences in cumulative biological risk profiles in a national sample of US adults: NHANES III (1988-1994). Soc Sci Med 66:72-87.

Seeman, T.E., 1996. Social ties and health: the benefits of social integration. Ann Epidemiol 6:442-51.

Seeman, T.E., Crimmins, E., Huang, M.H., Singer, B., Bucur, A., Gruenewald, T., Berkman, L.F., Reuben, D.B., 2004. Cumulative biological risk and socio-economic differences in mortality: MacArthur studies of successful aging. Soc Sci Med 58:1985-97.

Seeman, T.E., McEwen, B.S., Rowe, J.W., Singer, B.H., 2001. Allostatic load as a marker of cumulative biological risk: MacArthur studies of successful aging. Proc Natl Acad Sci U S A 98:4770-5.

Seeman, T.E., Singer, B.H., Rowe, J.W., Horwitz, R.I., McEwen, B.S., 1997. Price of adaptation--allostatic load and its health consequences. MacArthur studies of successful aging. Arch Intern Med 157:2259-68.

So, A., Thorens, B., 2010. Uric acid transport and disease. J Clin Invest 120:1791-9.

Statistique suisse, 2012. Protection sociale. Statistique suisse.

Strazzullo, P., Puig, J.G., 2007. Uric acid and oxidative stress: relative impact on cardiovascular risk? Nutr Metab Cardiovasc Dis 17:409-14.

Stringhini, S., Berkman, L., Dugravot, A., Ferrie, J.E., Marmot, M., Kivimaki, M., SinghManoux, A., 2012. Socioeconomic status, structural and functional measures of social support, and mortality: The British Whitehall II Cohort Study, 1985-2009. Am J Epidemiol $175: 1275-83$. 
Stringhini, S., Dugravot, A., Kivimaki, M., Shipley, M., Zins, M., Goldberg, M., Ferrie, J.E., Singh-Manoux, A., 2011. Do different measures of early life socioeconomic circumstances predict adult mortality? Evidence from the British Whitehall II and French GAZEL studies. J Epidemiol Community Health 65:1097-103.

Stringhini, S., Sabia, S., Shipley, M., Brunner, E., Nabi, H., Kivimaki, M., Singh-Manoux, A., 2010. Association of socioeconomic position with health behaviors and mortality. JAMA 303:1159-66.

UNDP, 2011. Human Development Report 2011: Sustainability and Equity: A Better Future for All, in: United Nations Development Programme (Ed.). UNDP, New York, United States. Vassalle, C., Novembrino, C., Maffei, S., Sciarrino, R., De Giuseppe, R., Vigna, L., de Liso, F., Mercuri, A., Bamonti, F., 2011. Determinants of oxidative stress related to gender: relevance of age and smoking habit. Clin Chem Lab Med 49:1509-13.

World Bank, 2012. World Development Indicators. 
ESSEC Business School Avenue Bernard Hirsch BP 50105

95021 Cergy-Pontoise Cedex France

Tél. +33(0)134433000

$\mathrm{Fax}+33(0) 134433001$

www.essec fr

\section{ESSEC Executive Education}

CNIT BP 230

92053 Paris-La Défense France

Têl. + $33(0) 146924900$

Fax +33 (0)1 46924990

http://formation.essec.fi

ESSEC Business School

Singapore Campus

100 Victoria Street

National Library Building \# 13-02

Singapore 188064

essecasia@essec.fr

Tél. +6568849780

Fax +6568849781

www.essec.edu

Informations

+33 (0)134433358

www.essec.fr

research.center@essec.fr

ISSN 1291-9616 